\title{
REGULARIZAÇÃO FUNDIÁRIA E CIDADE SUSTENTÁVEL: PANORAMA SOBRE TENDÊNCIAS ATUAIS DA URBANIZAÇÃO BRASILEIRA
}

\author{
Carlos Eduardo de Souza Cruz *
}

\section{RESUMO}

O objetivo deste artigo é realizar um panorama sobre o processo de urbanização brasileiro, destacando o desafio à consecução do direito à cidade que é motivado por aspectos que agravam a "questão urbana" no país, como os possíveis impactos do recente marco jurídico da regularização fundiária sobre o padrão de urbanização prevalecente no Brasil. A investigação teórico-normativa realizada sugere que a ênfase de uma regularização fundiária voltada prioritariamente à titulação tende a dificultar a implementação de ações que promovam um projeto estrutural de cidade sustentável no espaço urbano brasileiro.

Palavras-chave: Urbanização; Metropolização; Periferia urbana; Regularização fundiária; Cidade sustentável.

\section{LANDHOLDING REGULARIZATION AND SUSTAINABLE CITY: AN OVERVIEW OF THE PRESENT TENDENCIES OF BRAZILIAN URBANIZATION}

\begin{abstract}
The purpose of this paper is to provide an overview of the Brazilian urbanization process, highlighting the challenge to achieve the right to the city, which is motivated by aspects that aggravate the "urban question" in the country, such as the possible impacts of the recent legal milestone of the landholding regularization on the prevailing urbanization pattern in Brazil. The theoretical-normative approach suggests that the emphasis of a landholding regularization primarily oriented by formal ownership tends to hamper the implementation of actions that promote a structural project of sustainable city in the Brazilian urban space.
\end{abstract}

Key-words: Urbanization; Metropolization; Urban fringe; Landholding regularization; Sustainable city.

\section{INTRODUÇÃO}

Como uma das dimensões do processo de produção social do espaço, a urbanização apresenta-se como fenômeno essencialmente dinâmico, transformando a realidade socioespacial de novas maneiras e com diferentes intensidades, à medida que ela mesma, a urbanização, experimenta mudanças constantes na forma pela qual se manifesta. Daí depreende-se a necessidade de empreenderem-se esforços constantes para compreender

\footnotetext{
* Mestrando em Direito da Cidade pela Universidade do Estado do Rio de Janeiro (UERJ). Bolsista do CNPq. Atua junto ao Núcleo de Ensino, Pesquisas e Extensão em Direito da Cidade (NEPEC-UERJ). E-mail: carloseduardosc@gmail.com
} 
esse fenômeno, o qual, em plena "Era Urbana" mundial, exige novas interpretações para tornar a experiência prática passível de entendimento.

Este artigo volta-se ao tema da urbanização brasileira, perscrutando suas relações com as expectativas associadas a uma cidade sustentável, em face de mudanças recentes no estatuto jurídico urbanístico. Problematizando as tendências atuais de reprodução do padrão de urbanização periférica, este artigo objetiva realizar panorama sobre o processo de urbanização do país, destacando o desafio à consecução do direito à cidade que é motivado por aspectos que agravam a "questão urbana", notadamente os possíveis impactos da lei federal n. 13.465/2017 sobre o padrão de urbanização prevalecente no Brasil.

Para tanto, foram estabelecidas duas etapas de investigação, para a qual foi utilizado viés exploratório e hipotético-dedutivo: a primeira delas consiste em investigação teórica preliminar, voltada ao universo acadêmico-científico, para assentar conceitos e para realizar as análises necessárias ao desenvolvimento; a segunda, investigação normativa, voltada especialmente ao ordenamento urbanístico constitucional e infraconstitucional, para conferir os contornos jurídicos adequados às análises propostas. Em termos de organização, além desta introdução e das conclusões, este artigo encontra-se dividido em três seções. A primeira delas refere-se a percurso histórico, a fim de estabelecer os principais parâmetros para compreender o processo de urbanização brasileiro, mormente seu padrão socioespacial. $\mathrm{Na}$ segunda seção, analisa-se de que maneira o padrão de urbanização periférica desafia o projeto de cidade sustentável, o qual pode ser depreendido dos objetivos de desenvolvimento urbano do país. Na última seção, investiga-se o modo pelo qual a regularização fundiária plena revela-se como condição para a consecução de uma cidade sustentável, analisando com especial atenção mudanças recentes do marco jurídico referente a esse instrumento de política urbana.

\section{O PROCESSO DE URBANIZAÇÃO BRASILEIRO E A CONSOLIDAÇÃO DE SEU PADRÃO SOCIOESPACIAL}

O processo de urbanização experimentado pelo Brasil apresentou diferentes fases, ao longo da história do país. A esse respeito, dois grandes períodos podem ser destacados. $\mathrm{O}$ primeiro deles ocorreu da época colonial até as primeiras décadas do século XX. O segundo, por sua vez, refere-se ao processo que passou a ter lugar, de maneira progressiva, após os anos de 1930. Esses dois períodos distinguem-se fundamentalmente pelo componente estrutural que caracteriza a urbanização em sentido estrito, componente que esteve ausente 
no primeiro período e constituiu a base do segundo. De fato, a urbanização verificada durante o primeiro período, isto é, da colonização portuguesa à Primeira República, correspondeu a processo de urbanização em sentido amplo, que denota a formação e o crescimento de centros urbanos associados a mero ajuntamento de múltiplas atividades sociais em uma dada localidade (GOTTDIENER e BUDD, p. 184); nesse sentido, o processo urbanizante ocorrido, no período em análise, encontrou-se desprovido das complexas relações estruturais que, em conformidade com mudanças do modelo sociopolítico e econômico do país, criaram as condições para o surgimento de um novo tipo de urbanização, de sentido estrito, durante o século XX.

É conhecido o fato de que o espaço urbano, no período colonial, não apresentou a centralidade detida pelas cidades na atualidade (FILHO, 1968; HOLANDA, 2004). A principal razão disso era a marcante preponderância do espaço rural naquela sociedade, o que correspondia ao modo de organização socioeconômica e cultural promovido pela colonização portuguesa. Não deve surpreender, portanto, que, naquela época, a vida dos centros urbanos fosse marcada por natureza intermitente e até por certo estigma, já que o maior nível das atividades urbanas dependia sobremaneira das necessidades das famílias rurais de deslocarem-se para esses centros, seja por ocasião de festas ou para a realização de negócios ocasionais (HOLANDA, 2004). Inclusive, de acordo com a interpretação de Gilberto Freyre (2006), a família patriarcal teria exercido função proeminente na sociedade colonial, constituindo "órgão da formação social brasileira", ao exercer diferentes funções sociopolíticas e econômicas, o que impactou a própria dinâmica de urbanização do território. Nesse sentido, a análise de Freyre aproxima-se daquela realizada por Oliveira Vianna (1987) acerca do centrifuguismo rural e antiurbano que teria caracterizado a formação colonial do país, aspecto que esteve assentado sobre as relações que este autor estabeleceu entre família, latifúndio, paternalismo e ausência de consciência política e cívica na sociedade da colônia.

Nessas condições, o processo de formação de centros urbanos encontrava óbices estruturais à sua aceleração e a seu espraiamento, ainda que as cidades, naquela época, constituíssem o lócus da Administração colonial. Com efeito, a colonização portuguesa, na América, empreendeu modelo econômico que, ao inibir a circulação de renda no interior da colônia (FURTADO, 2007), criou obstáculos ao desenvolvimento de atividades socioeconômicas consideradas essenciais ao alastramento do fenômeno urbanizante.De acordo com Boris Fausto (2010), o interesse mercantilista da metrópole portuguesa por rápido enriquecimento conformaria o modo de organização da canavicultura, que passou a 
constituir a principal atividade econômica da economia colonial (FURTADO, 2007). Por esse motivo, a produção deveria ser feita em larga escala, o que geraria três importantes consequências para a organização da sociedade colonial e, não menos, para a formação histórica brasileira. A primeira delas foi a ênfase monocultora, que se relacionaria às tendências históricas de hiperespecialização produtiva voltada ao mercado externo; a segunda foi o uso de grandes propriedades fundiárias, que, por sua vez, associa-se à estrutura fundiária altamente concentrada legada pelo sistema das sesmarias; por fim, uma das duradouras consequências desse modo de organização foi a utilização da mão de obra escrava, na medida em que o modelo econômico não se mostrava atrativo à mão de obra imigrante, livre e assalariada.

Especificamente, cumpre observar que as dimensões do engenho de açúcar criaram condições para sua autossuficiência (FURTADO, 2007), o que limitou consideravelmente o desenvolvimento econômico do território e a superação do centrifuguismo rural, retardando a dinâmica urbanizante. Isso foi agravado pela orientação exportadora da economia do açúcar, o que, em verdade, se encontra na base não apenas da tradicional inserção econômica internacional periférica do Brasil, mas também dos significativos óbices ao desenvolvimento do mercado interno brasileiro. A superação dessas estruturas socioeconômicas viria a tornarse objetivo nacional especialmente a partir dos anos de 1930.

A inibição do fluxo de renda, no interior da colônia, e a logística produtiva voltada ao exterior respondem, em grande medida, pelas tradicionais deficiências da rede urbana brasileira, marcada historicamente pela simplicidade funcional de seus centros, pela fragilidade de suas interconexões e pela excessiva concentração de atividades socioeconômicas em poucas cidades litorâneas, tendo-se em vista, em particular, a implantação da canavicultura nas terras férteis do massapê nordestino (FILHO, 1968; SCARLATO, 1996). Esses aspectos caracterizam, de maneira geral, a urbanização ocorrida, na América Portuguesa, e conformam grande parte do legado urbano passado ao Brasil Independente. Não obstante, é preciso destacar diferenças sensíveis quanto ao modo de surgimento de vilas e mesmo da morfologia urbana apresentada por algumas partes do território, em diferentes momentos da longa história colonial. A região das minas, por exemplo, sobretudo no século XVIII, apresentou maior dinâmica urbanizante e maior complexidade funcional de sua rede urbana, quando comparada àquela gerada pela economia do açúcar (FILHO, 1968; FAUSTO, 2010). Na medida em que as minas se encontravam em regiões interioranas, a própria logística de escoamento da produção incentivou o surgimento 
de núcleos urbanos, ao longo das rotas entre os centros produtores e os portos exportadores. Além disso, ante as oportunidades de enriquecimento pessoal, houve significativo fluxo migratório para essas regiões, o que estimulou a diversificação social e econômica das cidades mineiras, com impactos, inclusive, intrarregionais.

A Independência, em 1822, não romperia com a estrutura socioeconômica colonial que restringia a intensificação da urbanização do território. Ao contrário, o período imperial consolidou as bases agrárias da América Portuguesa, notadamente por meio de dois aspectos principais. O primeiro deles foi o advento da economia do café, que conferiu sustentação econômica ao regime monárquico, aprofundando o modelo da monocultura agroexportadora, latifundiária e escravocrata. O segundo desses aspectos foi a constituição de uma elite rural nacional, que, de maneira crescente, pôde patrocinar seus interesses junto à administração do regime (SODRÉ, 1998), como ocorreu com a política fundiária regressiva estabelecida em 1850 (MOTTA, 2009) e a tardia Abolição em 1888. Assim sendo, não surpreende que, ao final do século XIX, a população urbana brasileira equivalesse a aproximadamente $10 \%$ da população total (SANTOS, 1993). A despeito disso, é importante considerar que a sociedade do período imperial tornava-se, aos poucos, mais complexa, sobretudo quando comparada ao período colonial. Em particular no Segundo Reinado, houve maior diversificação nas cidades, com incremento das classes médias urbanas, surgimento de atividades industriais e mudanças espaciais significativas provocadas pela crescente mecanização, especialmente nas regiões próximas à Corte (FAUSTO, 2010).

De todo modo, demorariam ainda algumas décadas para que a sociedade brasileira pudesse experimentar processo estrutural de urbanização, o que demandava superar óbices de regimes que defendiam, com prioridade, interesses agrários. Isso ficou evidente, após a Proclamação da República, em 1889, quando, apesar das progressivas transformações sociais, sobretudo relacionadas à introdução do trabalho assalariado, à intensificação da imigração e ao incremento das classes médias, foi preciso ocorrer uma "cisão oligárquica" (FAUSTO, 1997) para que um novo horizonte de desenvolvimento socioeconômico e espacial pudesse ter lugar no país.

Durante a Primeira República, o processo de diversificação social continuou crescente, em que pese o regime ainda constituir-se essencialmente agrário. A política de valorização do preço do café e sua consequente "socialização das perdas" (FURTADO, 2007) constituem evidências do agrarismo como matriz sociopolítica daquela época, o qual ainda retardava, de diferentes maneiras, a intensificação das atividades econômicas tidas 
como pré-condições à urbanização estrutural do território. Sendo assim, compreende-se com maior clareza a afirmação de Décio Saes (1975), no sentido de que um projeto industrializante seria extrassistêmico na Primeira República. Por isso, inclusive, é preciso conceber com reservas o aumento da atividade industrial, na Primeira República, sobretudo por ela estar significativamente dependente da dinâmica da economia agroexportadora, que ainda constituía o centro dinâmico da economia nacional (FURTADO, 2007; GREMAUD et al, 2011).

Se um projeto industrializante era politicamente extrassistêmico, na Primeira República, socialmente ele era, cada vez mais, uma necessidade. A razão disso foram as inevitáveis transformações socioeconômicas e políticas que se seguiram notadamente à introdução do trabalho assalariado, às ondas imigratórias e às próprias desestabilizações provocadas por um regime descentralizado e carecedor de sentido nacional, em que passaram a ser prevalecentes os interesses da oligarquia paulista. Uma articulação entre oligarquias regionais descontentes, setores das Forças Armadas e das classes médias iria gerar uma mudança de regime inédita, na história brasileira (FAUSTO, 1997), o que seria determinante para o padrão de urbanização a ser consolidado no país durante o século XX.

A Revolução de 1930 constituiu momento de ruptura com as estruturas de um modelo econômico que obstaculizava transformações profundas no espaço urbano brasileiro. Afinal, o "Estado de Compromisso" (FAUSTO, 2010) que se seguiu à Primeira República permitiu a diversificação de interesses, no âmbito da esfera governamental, o que significou a releitura dos objetivos nacionais. Naquele momento, a ênfase voltou-se ao desenvolvimento do mercado interno e à industrialização do país, o que estava em consonância com os interesses de diferentes camadas sociais que, aos poucos, passaram a demandar oportunidades de trabalho e de geração de riqueza que o modelo agroexportador não conseguia satisfazer (IANNI, 1963). Nesse sentido, por exemplo, encontravam-se os interesses econômicofinanceiros da crescente burguesia industrial, os interesses profissionais das classes médias e populares, bem como os interesses estratégicos de setores militares e do próprio núcleo político do regime. É importante observar que os interesses dos cafeicultores precisaram ser defendidos também, na medida em que a renda gerada pelo setor primário seria fundamental ao projeto industrializante (FURTADO, 2007; GREMAUD et al, 2011).

Esse quadro sociopolítico e econômico que se desencadeou, de maneira particular, a partir dos anos de 1930, sustentou o processo estrutural de industrialização e de urbanização do território, contrastando-se com o sistema agrário precedente. De fato, a industrialização 
constituiria objetivo nacional de sucessivos governos, sobretudo no período desenvolvimentista da segunda metade do século passado, quando se aprofundou a estratégia de industrialização por substituição de importações (TAVARES, 1986). A transformação da base técnico-científica do território (SANTOS, M. e SILVEIRA, 2010) foi crescentemente acompanhada por uma nova dinâmica urbanizante, que se intensificou de maneira inédita. $\mathrm{O}$ complexo social da industrialização (SANTOS, M., 1993) marcou o processamento estrutural da urbanização brasileira, gerando amplas consequências socioespaciais, particularmente porque a intensificação da urbanização ocorreu sobre a deficiente rede urbana herdada dos períodos anteriores, o que acentuou problemas históricos do espaço urbano brasileiro.

Em menos de meio século, a população brasileira iria tornar-se majoritariamente urbana, o que foi constatado nos anos de 1970. Dois aspectos principais respondem pelo acelerado crescimento da população urbana. De um lado, estiveram as amplas dimensões do êxodo rural ocorrido no país, que se devem, sobretudo, ao impacto da modernização da agricultura no espaço rural, desarranjando esquemas produtivos que fixavam a população no campo (SCARLATO, 1996), bem como à atratividade gerada pela vida urbana, lócus de mais oportunidades de inserção econômico-profissional e de crescente gozo de direitos, como os trabalhistas (SINGER, 1987). De outro lado, é preciso ressaltar fatores que impactaram o crescimento vegetativo da população urbana, como a imigração estrangeira e as melhores condições relativas de vida nas cidades.

A urbanização acelerada da segunda metade do século passado não ocorreu de maneira uniforme no território nacional; a região Nordeste, por exemplo, em face de suas estruturas socioeconômicas particulares, levaria mais tempo para evidenciar as taxas de crescimento urbano experimentadas pelas regiões Sudeste e Sul. De todo modo, ao cabo do século, todas as regiões do país confluíriam para o padrão urbanizante, marcado por elevada população urbana e sua significativa concentração em poucas grandes cidades, o que gerou o fenômeno da metropolização ou urbanização concentrada (SANTOS, M., 1993). A metropolização deve ser entendida como consequência de uma rede urbana historicamente frágil, sem complexidade funcional e bastante dependente da projeção exercida pelas capitais dos estados (CORRÊA, R., 2006). Esse é o quadro que foi agravado pela urbanização acelerada do século passado, que somente seria atenuada, nos anos de 1980, quando o crescimento vegetativo da população urbana desacelerou e a lógica das "deseconomias de aglomeração" passou a impactar os fluxos de investimento produtivo, gerando relativo processo de desconcentração urbana e econômica, movimento caracterizado como 
desmetropolização (SANTOS, M., 1993). A relatividade desse movimento deve-se, sobretudo, ao fato de que, apesar do maior crescimento das cidades médias, verificado em tempos recentes, as metrópoles continuam a crescer de maneira significativa, o que limita as possíveis dimensões do referido processo de desmetropolização.

\section{A URBANIZAÇÃO PERIFÉRICA E O DESAFIO À CIDADE SUSTENTÁVEL}

Desde os anos de 1980, inclusive por comando constitucional, impõe-se a superação das graves consequências geradas pelo intenso processo urbanizante que marcou a segunda metade do século XX e que gerou, no Brasil, um tipo de urbanização concentrada que foi responsável pela presença de morfologias espaciais específicas, como a macrocefalia da rede urbana e a metropolização (SCARLATO, 1996). A progressiva desaceleração da urbanização foi contemporânea à mudança de regime, no país, conquista que por tanto tempo concentrou a atenção e os esforços da sociedade engajada. Uma vez iniciada a redemocratização, tornouse especialmente difícil contornar o passivo urbano acumulado em meio século de urbanização acelerada. As consequências que foram acumuladas, nesse período, conformam, em grande medida, a chamada "questão urbana", que ainda impõe óbices ao desenvolvimento socioeconômico e que desafia o ideário da reforma urbana no Brasil (CALDAS, 2015).

Por certo, as condições de vida da população, particularmente nos grandes municípios, dominam o debate relativo à temática urbana. Essa constatação não deve surpreender, na medida em que a experiência de uma industrialização com baixos salários (MARICATO, 1996) e de um intenso processo de urbanização, que ocorreu sobre uma rede urbana estruturalmente frágil, tornou as cidades, e particularmente os grandes municípios, “criadoras de pobreza" (SANTOS, M., 1993, p. 10). O crescimento das metrópoles brasileiras fez-se acompanhar, em grande medida, pelo processo de periferização da população, responsável por uma realidade de vida urbana marcada por significativa inefetividade no gozo de direitos sociais e coletivos. Práticas como a autoconstrução e a acentuada irregularidade urbanística ainda marcam o crescimento das periferias urbanas, ao lado da forte carência de infraestrutura e de acesso aos serviços públicos (MARICATO, 1996). Em verdade, o tipo de urbanização periférica evidencia o padrão de segregação socioespacial das grandes cidades do país (HOLSTON, 2013), caracterizado por elevada concentração de equipamentos urbanos e de dinamismo econômico em áreas centrais e valorizadas. Esse padrão torna ainda 
mais complexa a gestão territorial das grandes cidades, as quais, em geral, experimentam continuada expansão de suas manchas urbanas, o que pressiona as contas públicas e agrava o quadro socioambiental nessas localidades.

A precariedade do saneamento básico, por exemplo, é bastante elucidativa da problemática urbana associada ao padrão de urbanização periférica consolidado no país. De acordo com o Sistema Nacional de Informações sobre Saneamento divulgado pelo Ministério das Cidades, aproximadamente metade da população tem acesso à coleta de esgoto, do qual apenas uma pequena parcela passa por sistemas de tratamento (SNIS, 2018). O impacto ambiental disso é muito evidente, em particular nas periferias dos grandes centros urbanos. A gravidade das condições de saneamento ambiental, no contexto do padrão de urbanização periférica, revela-se ainda pela predominância das comunidades carentes do país em áreas ambientais que deveriam ser protegidas, em particular porque o mercado imobiliário formal tende a rejeitar essas áreas como foco de investimentos (MARICATO, 2011, p. 179).

Cumpre observar que muitos dos problemas associados ao passivo socioambiental gerado pelo processo urbanizante, como é o caso da precariedade da rede de saneamento básico, das dificuldades relativas à mobilidade da população, da carência de equipamentos urbanos e da frágil política de moradia, de modo geral, apresentam efeitos-cascata, isto é, eles abrangem de maneira sistemática a sociedade. No caso das deficiências de saneamento básico, por exemplo, o Sistema Nacional de Saúde (SUS) tende a ser sobrecarregado, uma vez que a má coleta e o mau tratamento de esgoto afetam negativamente a dimensão preventiva das políticas de saúde pública prestadas à população.

Em particular, a superação da questão urbana brasileira não pode prescindir da capacidade dos entes federados de realizarem suas competências constitucionais e legais em matéria urbana e regional, em conformidade com a repartição de competências prevista no texto constitucional, ainda que isso seja dificultado pela própria capacidade técnicofinanceira desses entes (AZEVEDO, 2006). O federalismo simétrico estabelecido na Constituição não encontra correspondência com as condições reais de atuação, por parte dos distintos entes federados, o que, no caso dos municípios, foi agravado pela ampliação de competências que lhes foi atribuída pela Constituição de 1988, em especial no que se refere à formulação e à execução da política urbana, âmbito em que prevalece o interesse municipal sobre os interesses dos demais entes. A experiência prática do federalismo brasileiro revelase, pois, assimétrica, tendo-se em vista as reais condições de governança dos entes federados, destacando-se negativamente a significativa dependência de pequenos e de médios 
municípios quanto às transferências e às assessorias intergovernamentais. Os estados também não escapam a muitas das deficiências apresentadas pelos municípios, o que se mostra particularmente grave, tendo-se em vista $o$ fato de os entes estaduais estarem constitucionalmente incumbidos de criar as regiões metropolitanas e, sobretudo após o Estatuto da Metrópole, de engajar-se na governança interfederativa. Considerando a grave crise financeira que, há décadas, acomete a muitos dos estados da federação (SANTOS, A., 2017), é possível compreender a dimensão do desafio de colocar em prática uma efetiva coordenação federativa para fins de desenvolvimento dos espaços metropolitanos, os quais concentram, em grande medida, problemas de ordem socioambiental derivados da urbanização brasileira.

De múltiplos pontos de vista, portanto, o padrão de urbanização desafia a consecução da ideia de cidades sustentáveis no país. O viés sistemático, em relação aos múltiplos problemas das cidades brasileiras, encontra-se na base dos indicadores de sustentabilidade urbana, criados pela Associação Brasileira de Normas Técnicas (ABNT, 2017), por meio da NBR ISO 37120:2017. Essa norma contém parâmetros para que seja possível aferir a conformidade das cidades ao padrão de comunidades sustentáveis que foi tomado como referência pela instituição. Isso significa conferir maior concretude à noção de cidades sustentáveis, que deve servir de importante referencial para as ações públicas e privadas voltadas ao desenvolvimento humano no espaço urbano brasileiro.

A sustentabilidade urbana, como plataforma política, tem significativas conexões com o movimento pela reforma urbana que orientou a construção do arcabouço normativo relativo à política urbana no Brasil. De modo particular, esse ideário postula um modelo includente e redistributivista de cidade, voltando-se contra a segregação socioespacial que responde pelos elevados índices de desigualdade no espaço urbano brasileiro (SAULE JÚNIOR e UZZO, 2012). Afinal, como afirmou Milton Santos (1993, p. 10), “a pobreza não é apenas o fato do modelo socioeconômico vigente, mas, também, do modelo espacial”.

De fato, o Movimento Nacional da Reforma Urbana (MNRU), criado em 1985, congregou diversos atores da sociedade civil que defendiam nova ética para o espaço urbano brasileiro, condenando especialmente o uso especulatório da terra nas cidades. Voltado à redução da injustiça social, o MNRU passou a articular uma importante pauta relativa à promoção da cidadania no meio urbano, ao estabelecimento de instrumentos jurídicopolíticos para aperfeiçoar a governança das cidades e à defesa de uma concepção progressista de experiência urbana, essencialmente vinculada à noção lefebvriana de direito à cidade e à 


\section{REGULARIZAÇÃO FUNDIÁRIA E CIDADE SUSTENTÁVEL: PANORAMA SOBRE TENDÊNCIAS ATUAIS DA URBANIZAÇÃO BRASILEIRA}

ampliação da participação social (SOUZA, 2015). A matriz lefebvriana de direito à cidade inspirou muitas das ações que redundaram na inserção de um capítulo específico para a política urbana, no texto constitucional, em que se reconhece a funcionalização da propriedade urbana e da própria cidade.

Para Henry Lefebvre (2016), o direito à cidade significa o direito à vida urbana, isto é, direito ao gozo do produto social do espaço urbano, obra coletiva a ser entendida por seu valor de uso, e não de troca. Em outras palavras, isso significa um direito a não ser excluído do que a vida em comunidade é capaz de gerar, com o devido respeito à liberdade e à individualização. De acordo com Charlotte Mathivet (2010), o direito à cidade não se trata de direito novo, devendo ser compreendido como plataforma política que propugna o acesso equitativo a direitos no espaço urbano. Não sendo estanque, o direito à cidade evolui, à medida que mudanças sociais promovem o rearranjo da sociedade, o que evidencia a natureza inclusiva desse conceito essencialmente coletivo. O recente Plano Diretor do município de São Paulo, em seu artigo 5o, parágrafo 5o, estabelece parâmetros para o entendimento de um conceito operacional de direito à cidade: "Direito à Cidade compreende o processo de universalização do acesso aos benefícios e às comodidades da vida urbana por parte de todos os cidadãos, seja pela oferta e uso dos serviços, equipamentos e infraestruturas públicas" (SÃO PAULO, 2014).

É inegável que a sustentabilidade, que se firmou como conceito transversal em princípios dos anos de 1990, no âmbito das conferências da ONU sobre o meio ambiente e o desenvolvimento, constitua uma das bases atuais do direito à cidade. Isso está particularmente evidente, por exemplo, na Carta Mundial pelo Direito à Cidade, firmada em 2004, por amplo conjunto de movimentos sociais de atuação internacional voltada à temática urbana. Em seu artigo número um, item dois, a Carta (VV.AA., 2004) estabelece: "The Right to the City is defined as the equitable usufruct of cities within the principles of sustainability, democracy, equity, and social justice”. O próprio Estatuto da Cidade, que, desde 2001, institui normas gerais de direito urbanístico no Brasil, prevê a garantia do direito a cidades sustentáveis dentre as diretrizes gerais estabelecidas à política urbana. De acordo com o inciso um do art. 2o do Estatuto (BRASIL, 2001), o direito a cidades sustentáveis deve ser compreendido como "direito à terra urbana, à moradia, ao saneamento ambiental, à infraestrutura urbana, ao transporte e aos serviços públicos, ao trabalho e ao lazer, para as presentes e futuras gerações". Sendo assim, depreende-se que o Estatuto da Cidade 
claramente articula os conceitos de função social da cidade e da propriedade, que foram defendidos pelo MNRU, ao de cidades sustentáveis (KRAUSE e COSTA, 2017).

As dificuldades de superação da questão urbana, na atualidade, demonstram o desafio representado pela continuidade do padrão de urbanização periférica à efetividade do direito à cidade e, consequentemente, ao usufruto pelos cidadãos de uma cidade sustentável.

\section{A REGULARIZAÇÃO FUNDIÁRIA PLENA COMO CONDIÇÃO DA CIDADE SUSTENTÁVEL}

A Constituição de 1988 representou importante conquista jurídico-política pela sociedade brasileira. Quanto à temática urbana, em particular, o inédito capítulo sobre política urbana gerou consideráveis expectativas positivas quanto ao futuro das cidades do país. Inclusive, desde um ponto de vista sistemático do ordenamento constitucional, particularmente à luz das diretrizes de desenvolvimento urbano e regional, princípios fundamentais e dos direitos sociais e coletivos, seria possível depreender a constitucionalização de um direito da cidade, fundado precisamente na normatividade urbanístico-constitucional ensejada pela redemocratização (CORREIA, 2015). Não obstante, nos últimos anos, as expectativas geradas, no contexto de redemocratização, têm sido frustradas, notadamente em razão da continuidade de muitos dos óbices à eficácia do planejamento e da governança urbanas no país (VILLAÇA, 2004), seja pelo ainda baixo perfil da questão urbana, no âmbito da agenda de desenvolvimento nacional, seja por questões ideológicas que limitam a efetividade da função social da propriedade urbana e de um modelo de cidade que priorize o equitativo acesso aos benefícios e às comodidades da vida urbana. Essas constatações justificam, em grande medida, o posicionamento daqueles que apontam existir verdadeiro impasse da política urbana no Brasil (MARICATO, 2011).

Mais especificamente, a crescente frustração explica-se pela ausência de eficácia da normatividade urbanística no cotidiano das cidades brasileiras. A rigor, a falta de eficácia e mesmo a falta de efetividade de normas urbanísticas não constitui novidade, na história urbana nacional, constituindo precisamente uma das características do padrão de urbanização periférica analisado. O diferencial, após a redemocratização, foi o fato de as frustrações estarem associadas ao arcabouço jurídico de vanguarda que foi criado nas últimas décadas (SANTOS, A., 2017), sendo destacável o advento do Estatuto da Cidade, em 2001, regulamentando o capítulo de política urbana da Constituição. Ante essa realidade, é cada 
vez mais frequente, dentre os especialistas, a opinião segundo a qual o elemento realmente necessário à superação da questão urbana é a ação política cidadã, que deve ser estimulada a controlar o Poder Público e a atuar em diferentes instâncias da sociedade civil, na defesa de um novo modelo de desenvolvimento urbano que se contraponha à significativa influência dos interesses de mercado sobre a governança urbana na contemporaneidade (HARVEY, 2012; MARICATO, 2013).

Sem embargo disso, é preciso reconhecer que as questões técnico-burocráticas preservam sua importância para a consecução de um desenvolvimento urbano que seja justo e sustentável; muitas delas, inclusive, como aquelas associadas ao universo jurídico, constituem a garantia do cidadão de que o Estado encontra-se vinculado a compromisso realmente transformador da sociedade, o que sinaliza um horizonte de ação pública e privada para fins de emancipação individual e coletiva. Nesse sentido, Cláudia Franco Corrêa (2015) observa a necessidade de colocar em prática uma estruturação jurídico-urbanística dialógica, isto é, um sistema de cooperação entre o Estado e a sociedade para fins de promoção das funções sociais da cidade, rompendo com o dirigismo estatal que foi prevalecente durante grande parte da história do planejamento urbano no país.

$\mathrm{O}$ crescimento das frustrações, em relação à legislação urbanística, não deve ocultar os avanços representados por uma série de instrumentos jurídicos que foram aprovados no Brasil. Esse é o caso da regularização fundiária, que, durante a primeira década deste século, foi marcada pela consolidação de modelo holístico voltado ao tratamento da questão fundiária urbana. Trazida como instrumento jurídico pelo Estatuto da Cidade, a regulamentação da regularização fundiária, no âmbito da lei 11.977/09, significou o estabelecimento de uma perspectiva sistemática referente ao tratamento das propriedades nas cidades brasileiras. Com visão de conjunto, o modelo estabelecido pela lei 11.977/09 criou as bases para o enfrentamento das várias dimensões que podem ser abrangidas pela regularização fundiária, como a dominial, focada na titulação da posse e da propriedade; a urbanístico-ambiental, em que se conciliam normas especiais de urbanização com parâmetros mínimos de sustentabilidade e de uniformização legal; e a social, cuja ênfase recai sobre as políticas públicas voltadas a conferir adequadas condições de vida às populações-alvo, notadamente o direito à moradia.

De fato, expectativas positivas surgiram, quanto ao tema da regularização fundiária urbana, com o advento do Estatuto da Cidade e da lei 11.977/09, sobretudo porque ambos os instrumentos normativos têm como norte a necessidade de efetivar a justiça social e a 
garantia de direitos, particularmente o direito à moradia (CORRÊA, C., 2015), no âmbito de um campo de atuação do Poder Público que nem sempre abrangeu esse tipo de orientação valorativa: na história brasileira, são antigas as tentativas de regularização da ocupação do solo, de modo geral, merecendo destaque a Lei de Terras de 1850, o Decreto-Lei 9.760/46, o Estatuto da Terra de 1964, a Medida Provisória 2.220/01 e a lei 11.481/07. A Lei de Terras, por exemplo, embora efetivamente suprisse o vácuo jurídico fundiário que caracterizou as primeiras décadas após a Independência, ao estabelecer o mecanismo de mercado como meio de aquisição de propriedades em sociedade profundamente desigual e ainda escravocrata, consolidou uma elevada concentração fundiária que explica, de modo significativo, a dimensão alcançada pelo êxodo rural e pela urbanização acelerada do século XX (HOLSTON, 2013).

Consolidado na década passada, o modelo de regularização fundiária urbana plena, isto é, aquela voltada ao tratamento holístico das questões fundiárias, abrangendo os aspectos dominiais, urbanístico-ambientais e sociais, estava em conformidade, de um lado, com as necessidades materiais de superação da problemática urbana brasileira, gerada pelo padrão de urbanização periférica do país; de outro, demonstrava sua consonância com as necessidades normativas associadas ao direito à cidade e às funções sociais da cidade e da propriedade, que devem constituir parâmetro de validade do ordenamento infraconstitucional, tendo-se em vista o princípio da força normativa da Constituição e o desenvolvimento da jurisdição constitucional (CORREIA, 2015). Por essas razões, a recente aprovação da lei 13.465/17, que alterou o marco normativo da regularização fundiária urbana, notadamente a lei 11.977/09, apresenta-se como origem de justificadas apreensões. Em primeiro lugar, pelo fato de as amplas mudanças promovidas pela nova legislação revogarem, em grande medida, o arcabouço normativo da regularização fundiária aperfeiçoado há menos de uma década. É razoável afirmar que a experiência com o modelo anterior foi relativamente curta, o que significou pouco tempo para que o modelo pudesse ser amplamente testado e viabilizado por agentes públicos e privados. Em segundo, porque o viés holístico da legislação anterior foi superado pela ênfase atualmente atribuída ao aspecto da titulação, o que, em tese, não se mostra condizente com as necessidades sistemáticas da questão urbana do país.

Ao ampliar as possibilidades de efetivação do modelo de regularização fundiária estrita, sobretudo por meio da desburocratização de procedimentos voltada à rápida escrituração de proprietários urbanos, a nova legislação colocou em prática um modelo de titulação que não se encontra necessariamente preocupado com as questões urbanísticas em 
seu conjunto. O contraste disso com o modelo precedente é bastante evidente, uma vez que as irregularidades que o modelo da lei 11.977/09 procurava atacar eram associadas ao título, isto é, notadamente à falta de registro cartorial e à insegurança da posse; também estavam associadas à segurança edilícia, tendo-se em vista, sobretudo, as amplas dimensões da prática de autoconstrução nas periferias urbanas; e, igualmente, se associavam às questões urbanísticas, que estão relacionadas à abrangente noção de cidade sustentável.

Assim sendo, é compreensível que se avolumem opiniões, no sentido de que o modelo trazido pela lei 13.465/17 alterou fundamentalmente o objetivo maior da regularização fundiária que pautava o marco jurídico anterior; ou seja, passou-se de modelo que conferia ênfase ao direito de acesso aos benefícios e às comodidades da vida urbana, particularmente o direito à moradia, para um modelo centrado no desenvolvimento econômico-financeiro representado pela escrituração da propriedade, em que não se vislumbra efetiva ênfase à viabilização das demais dimensões da regularização das propriedades urbanas; nesse sentido, não deve surpreender que a nova legislação permita o uso de recursos dos Fundos de Habitação de Interesse Social para ressarcir isenções cartorárias, diminuindo, ao menos em termos relativos, o montante a ser efetivamente utilizado em ações de infraestrutura urbanística.

Ao analisar o modelo da lei 13.465/17, Arícia Fernandes Correia (2017) caracteriza-o como de titulação independente de urbanização. A mudança de modelo seria depreendida, particularmente, da relevância conferida pela nova lei ao princípio econômico da eficiência no uso e na ocupação do solo, agora arrolado entre os objetivos da regularização fundiária urbana; da busca por maior celeridade na tramitação cartorária, ao passo em que se ampliam os espaços de atuação política; bem como dos impactos do novel instituto da legitimação fundiária. A nova legislação, ao tornar a titulação o objetivo maior da ação pública voltada à regularização fundiária, demonstra estar afinada com uma perspectiva essencialmente econômico-financeira sobre a política urbana. Uma vez aplicado ao regime fundiário urbano, essa perspectiva conecta-se ao ideário que defende a consolidação de um regime de propriedade formal como pressuposto ao desenvolvimento socioeconômico, tendo-se em vista que a irregularidade fundiária obstaculizaria a efetiva exploração do potencial econômico associado ao conjunto de propriedades fundiárias regulares e irregulares (SOTO, 2001).

Não obstante, as relações estabelecidas entre a consolidação de um sistema de propriedade formal e o desenvolvimento econômico basearam-se, sobretudo, na experiência 
histórica dos países desenvolvidos. Esse fato deve ser visto com atenção, pois não é recomendável projetar, para países em desenvolvimento, a experiência de países centrais, os quais alcançaram seu patamar de desenvolvimento por meio de processos e de circunstâncias de formação sociopolítica significativamente singulares. A mudança do marco jurídico da regularização fundiária, conforme sucedeu, é ainda preocupante, à luz de pesquisas que versaram sobre a política de titulação em massa, voltada justamente à consolidação do regime de propriedade formal. O Peru constitui estudo de caso emblemático dessa política, nas últimas décadas, ante a força alcançada pelo ideário de titulação nesse país.

Julio Abel Calderón Cockburn (2013) realizou importante análise sobre a política de formalização da propriedade peruana, que foi colocada em prática, a partir de 1996, por meio de massiva formalização via concessão de títulos de propriedade. Em suas conclusões, o autor observa que o caso peruano superou a etapa da formalização, em face do registro de mais de 1,3 milhões de títulos em sete anos; no entanto, a conversão das propriedades legais em capital, que constitui o objetivo principal da política, ainda não pôde ser verificado. Em realidade, de acordo com Cockburn, poucos estudos avalizam o real impacto positivo da política de formalização, o que tornam muito incertos os impactos dessa política em sociedades em desenvolvimento. De toda sorte, o autor atribuiu os poucos resultados econômico-financeiros da política de formalização, realizada em bairros populares peruanos, à segmentação dos mercados financeiro e imobiliário, à baixa renda da população-alvo, aos custos superiores da formalidade em comparação aos custos da informalidade, à excessiva ênfase jurídica da política de formalização, bem como a excessiva crença na abertura do mercado aos proprietários titulados.

Em face dessas constatações, é especialmente preocupante o impacto do novo marco jurídico da regularização fundiária sobre as possibilidades de consecução de um projeto de cidade sustentável. Além de a nova legislação estar baseada em política de resultados inconclusivos, conforme a experiência ocorrida no Peru, que apenas superou a etapa de massiva formalização, a ênfase econômica subjacente a essa política revela-se pouco condizente com as múltiplas dimensões exigidas por um modelo de desenvolvimento urbano efetivamente sustentável, pautado por diretrizes inclusivas e redistributivistas. O justificado receio é o de que a regularização fundiária, voltada sobretudo a um objetivo econômicofinanceiro, reproduza modelo de desenvolvimento urbano que agrava o padrão periférico da urbanização brasileira, o que se revela significativamente prejudicial às despesas públicas e, 
em particular, aos índices de qualidade de vida da população residente nas periferias das grandes cidades do país, submetidas a tendências de exclusão socioeconômica e espacial.

\section{CONCLUSÕES}

A análise histórica do espaço urbano brasileiro permitiu compreender, em grande medida, as origens da "questão urbana" do país, o qual precisou superar as limitações estruturais à dinâmica urbanizante que prevaleceram, durante a maior parte da história nacional, para, enfim, empreender as bases de amplo e acelerado processo de urbanização e de industrialização do território, após a mudança de regime em 1930. Se, de um lado, a rápida urbanização significou uma conquista, por romper com o agrarismo que privilegiava a elite rural brasileira, de outro, a dinâmica urbanizante da segunda metade do século passado consolidaria um padrão de experiência de vida urbana injusta e insustentável para uma significativa parcela da população brasileira, que, já na década de 1970, tornava-se majoritariamente urbana.

Os processos de metropolização e de periferização, que marcaram a urbanização do território, a partir de meados do século XX, desafiam o projeto de cidade sustentável no país. Os altos índices de violência, de poluição e de imobilidade, e a grande carência de equipamentos urbanos, de acesso a serviços públicos e de oportunidades de moradia e de inserção econômico-profissional, sobretudo nas periferias das grandes cidades, representam a outra face do padrão de urbanização periférica consolidado no século passado. Nesse sentido, a continuada expansão das periferias urbanas, em decorrência de modelo de desenvolvimento urbano que segrega a população mais pobre das áreas centrais e valorizada, torna cada vez mais distante a concretização do direito à cidade, no Brasil, direito que deve ser entendido como plataforma política voltada à redução da injustiça social, à garantia de direitos e à fruição dos benefícios e das comodidades da vida urbana, que constituem parâmetros necessários a uma cidade que se pretenda ser sustentável.

Em que pese os avanços normativos quanto à temática urbanística que são representados, notadamente, pela Constituição e pelo Estatuto da Cidade, o impasse da política e do planejamento urbanos, no país, tem gerado justificadas frustrações para aqueles que vislumbraram novo horizonte para as cidades brasileiras, ante a recepção normativa de muitos dos fundamentos propugnados pelo movimento pela reforma urbana. A esse quadro de frustrações crescentes, somaram-se apreensões quanto aos possíveis impactos da lei 
13.465/17 sobre a realidade urbana do país. A análise realizada sugere que o novo marco jurídico da regularização fundiária, que se encontra voltado, sobretudo, à desburocratização da formalização do sistema de propriedades fundiárias, de acordo com perspectiva econômico-financeira sobre o espaço urbano que confere significativa relevância à noção de eficiência na ocupação do solo, tende a dificultar o estabelecimento de condições estruturais de sustentabilidade das cidades brasileiras.

A superação da ênfase conferida à regularização fundiária plena por uma política fundada, sobretudo, no aspecto dominial, representa um desafio especial ao projeto de cidades sustentáveis e, portanto, à consecução do direito à cidade no Brasil, gerando tendências ao aprofundamento de um padrão de urbanização periférica que amplifica a "questão urbana" brasileira, a significar a continuidade de um quadro urbano marcado pela injustiça social e por graves problemas ambientais que atentam contra os parâmetros contemporâneos acerca da boa qualidade de vida.

\section{REFERÊNCIAS BIBLIOGRÁFICAS}

ABNT, 2017. Comunidades sustentáveis. Disponível em: <http://www.abnt.org.br/imprensa/releases/5284-comunidades-sustentaveis>. Acesso em: 02 fev. 2018.

AZEVEDO, Sérgio. Desigualdades sociais e reforma do Estado: os desafios da gestão metropolitana no federalismo brasileiro. In: Sonia Fleury (org.). Democracia, Descentralização e Desenvolvimento: Brasil \& Espanha. São Paulo: FGV, 2006, p. 127186.

BRASIL, 2001. Lei n. 10.257, de 10 de julho de 2001. Estatuto da Cidade. Brasília, DF. Disponível em: <http://www.planalto.gov.br/Ccivil_03/Leis/LEIS_2001/L10257.htm>. Acesso em: 30 mar. 2018.

CALDAS, Maria Fernandes. Política urbana, ação governamental e a utopia da reforma urbana no Brasil [manuscrito] / Maria Fernandes Caldas. 2015, $271 \mathrm{f}$.

COCKBURN, Julio Abel Calderón. Los pobres urbanos y la propriedad: Políticas y resultados. Saarbrücken: Académica Española, 2013.

CORRÊA, Roberto Lobato. Estudos sobre a rede urbana. RJ: Bertrand Brasil, 2006.

CORRÊA, Cláudia Franco. Instrumentos de regularização fundiária nas favelas. In: Fábio de Oliveira Azevedo; Marco Aurélio Bezerra de Melo (orgs.). Direito Imobiliário: escritos em homenagem ao Professor Ricardo Lira. São Paulo: Atlas, 2015, p. 630-646. 
CORREIA, Arícia Fernandes. Constitucionalização do direito à cidade: direito fundamental à moradia, regularização fundiária e legitimação de posse. In: Fábio de Oliveira Azevedo; Marco Aurélio Bezerra de Melo (orgs.). Direito Imobiliário: escritos em homenagem ao Professor Ricardo Lira. São Paulo: Atlas, 2015, p. 647-681.

Direito da regularização fundiária urbana e autonomia municipal: a conversão da Medida Provisória n. 759/2016 na lei federal n. 13.465/2017 e as titulações da prefeitura da cidade do Rio de Janeiro no primeiro quadrimestre de 2017. Disponível em: <http://www.epublicacoes.uerj.br/index.php/geouerj/article/viewFile/32061/22979>. Acesso em: 28 mar. 2018.

FAUSTO, Boris. A Revolução de 1930: historiografia e história. São Paulo: Companhia das Letras, 1997.

L História do Brasil. São Paulo: Ed. USP, 2010.

FILHO, Nestor Reis. Contribuição ao Estudo da Evolução Urbana do Brasil (1500/1720). São Paulo: Ed. USP, 1968.

FREYRE, Gilberto. Casa-Grande e Senzala: formação da família brasileira sob o regime da economia patriarcal. São Paulo: Global, 2006.

FURTADO, Celso. Formação Econômica do Brasil. São Paulo: Companhia das Letras, 2007

GOTTDIENER, Mark; BUDD, Leslie. Key Concepts in Urban Studies. London: Sage, 2005 .

GREMAUD, Amaury Patrick et al. Economia brasileira contemporânea. Amaury Patrick Gremaud, Marco Antonio Sandoval de Vasconcelos, Rudinei Toneto Jr. São Paulo: Atlas, 2011.

HARVEY, David. Rebel cities: from the right to the city to the urban revolution. London: Verso, 2012.

HOLANDA, Sérgio Buarque de. Raízes do Brasil. São Paulo: Companhia das Letras, 2004.

HOLSTON, James. Cidadania insurgente: disjunções da democracia e da modernidade no Brasil. São Paulo: Companhia das Letras, 2013.

IANNI, Octavio. Industrialização e Desenvolvimento Social no Brasil. Rio de Janeiro: Civilização Brasileira, 1963.

KRAUSE, Cleandro; COSTA, Marco Aurélio. Estatuto da Ciudad: una década y medio de implantación, algunos resultados y un impasse en Brasil. In: Una visión general de las leyes nacionales en América Latina y Caribe: estudios de caso de Brasil, Colombia y Ecuador. Anacláudia Rossbach, Daniel Montandon (orgs.). São Paulo: Cities Alliance, 2017.

LEFEBVRE, Henri. O direito à cidade. Itapevi, SP: Nebli, 2016, p. 43-69. 
MARICATO, Ermínia. Metrópole na periferia do capitalismo: ilegalidade, desigualdade e violência. São Paulo: Hucitec, 1996.

O impasse da política urbana no Brasil. Petrópolis: Vozes, 2011.

É a questão urbana, estúpido! In: David Harvey; Ermínia Maricato et al. Cidades rebeldes: Passe Livre e as manifestações que tomaram as ruas do Brasil. São Paulo: Boitempo, 2013, p. 13-20.

MATHIVET, Charlotte. The right to the city: keys to understanding the proposal for "Another City is Possible". In: Ana Sugranyes; Charlotte Mathivet (ed.). Cities for all: proposals and experiences towards the right to the city. Santiago: HIC, 2010, p. 21-26.

MOTTA, Márcia Maria Menendes. Direito à terra no Brasil: a gestação do conflito (17951824). São Paulo: Alameda, 2009.

SANTOS, Milton. A Urbanização Brasileira. São Paulo: Hucitec, 1993.

; SILVEIRA, María Laura. O Brasil: território e sociedade no início do século XXI. Rio de Janeiro: Record, 2010.

SANTOS, Angela Moulin Simões Penalva. Política urbana no contexto federativo brasileiro: aspectos institucionais e financeiros. Rio de Janeiro: EdUERJ, 2017.

SAES, Décio. Classe Média e Política na Primeira República Brasileira (1889-1930). Rio de Janeiro: Vozes, 1975.

SÃO PAUlO (Município), 2014. Lei no 16.050, de 31 de julho de 2014. Política de Desenvolvimento Urbano e Plano Diretor Estratégico do Município de São Paulo. Diário Oficial da Cidade de São Paulo, Poder Executivo, São Paulo, SP, 2014.

SAULE JÚNIOR, Nelson; UZZO, Karina. The history of urban reform in Brazil. In: Ana Sugrayes; Charlotte Mathivet (org.). Cities for All: proposals and experiences towards the Right to the City. Santiago: HIC, 2010, p. 247-258.

SCARLATO, Francisco Capuano. População e urbanização brasileira. In: Jurandyr Luciano Sanches Ross (org.). Geografia do Brasil. São Paulo: USP, 1996. p. 381-465.

SINGER, Paul. Economia política da urbanização. São Paulo: Brasiliense, 1987.

SNIS, 2018. Diagnóstico dos serviços de água e esgoto - 2016. Disponível em: <http://www.snis.gov.br/diagnostico-agua-e-esgotos/diagnostico-ae-2016>. Acesso em: 30 mar. 2018.

SODRÉ, Nelson Werneck. Panorama do Segundo Império. Rio de Janeiro: Graphia, 1998

SOTO, Hernando de. O Mistério do Capital. Rio de Janeiro: Record, 2001.

Revista de Direito Urbanístico, Cidade e Alteridade | e-ISSN: 2525-989X | Salvador | v. 4 | n. 1 | p. 59 - 79 | 
SOUZA, Marcelo Lopes de. Mudar a cidade: uma introdução crítica ao planejamento e à gestão urbanos. Rio de Janeiro: Bertrand Brasil, 2015.

TAVARES, Maria da Conceição. Acumulação de capital e industrialização no Brasil. Campinas: Ed. Unicamp, 1986.

VIANNA, Oliveira. Instituições Políticas Brasileiras. 1 v. São Paulo: Eduuf, 1987.

VILLAÇA, Flávio. Uma contribuição para a história do planejamento urbano no Brasil. In: Csaba Deák; Sueli Ramos Schiffer (org.). O processo de urbanização no Brasil. São Paulo: USP, 2004, p. 171-243.

VV.AA. World Charter for the Right to the City. Disponível em: <http://www.righttothecityplatform.org.br/download/publicacoes/World\%20Charter\%20for $\% 2$ 0the\%20Right\%20to\%20the\%20City.pdf>. Acesso em: 30 mar. 2018. 